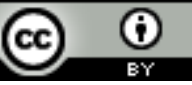

KATSAUS

\author{
Erika Lilja
}

\title{
Perinteisen vertaisarvioinnin vahvuuksia ja avoimen arvioinnin hyveitä
}

\author{
Avoin vertaisarviointi (open peer review), avoin tiede (open science), tieteel- \\ linen julkaiseminen (scientific publishing)
}

Erika Lilja; projektipäällikkö, INVEST-lippulaiva, (Turun yliopisto); väitöskirjatutkija, HEG, (Tampereen yliopisto)

Avoimuus on ollut tieteen periaate jo 1600- ja 1700 -luvun taitteesta lukien, jolloin (luonnon)tieteellinen vallankumous merkitsi siirtymää kohti avoimia periaatteita, kannustimia ja rakenteita, jotka johtivat tutkijoiden sitoutumiseen tieteellisen tiedon jakamiseen ${ }^{1}$. Avoin tiede ja siihen liittyvä avoin vertaisarviointi nykypäivän käsitteinä kytkeytyvät puolestaan tiiviisti digitaalisen teknologian kehitykseen ja sen mukanaan tuomiin saavutettavuuden, läpinäkyvyyden ja vuorovaikutteisuuden mahdollisuuksiin korkeatasoisen ja vaikuttavan tieteellisen tiedon tuottamisessa. Uudet mahdollisuudet haastavat muun muassa vallassa olevaa tieteellisen julkaisemisen järjestelmää ja perinteisiä tieteellisen vertaisarvioinnin käytäntöjä.

Avoimen vertaisarvioinnin tavoitteena on vastata perinteiseen julkaisemiseen ja vertaisarviointiin yhdistettyihin haasteisiin, kuten epäluotettavuus ja epäjohdonmukaisuus, hitaus ja kohtuuttomat kustannukset, vastuullisuus, julkaisemiseen liittyvät sosiaaliset vinoumat (ennakkoasenteet, konservatiivisuus, positiivisten tulosten julkaiseminen) sekä annettujen arviointilausuntojen alihyödyntäminen tieteen edistämisessä. Näihin haasteisiin on pyritty vastaamaan avointen identiteettien ja lausuntojen sekä osallistumisen ja vuorovaikutuksen keinoin. Vuorovaikutteisuuden ja läpinäkyvyyden edistämiseksi vertaisarvioituja artikkeleita voidaan esimerkiksi kommentoida avoimesti vertaisarvioinnin jälkeen tai vertaisarvioimattomia käsikirjoituksia voidaan julkaista välittömästi esimerkiksi arXiv-palvelimella. Avoimet alustat mahdollistavat artikkelin arvioinnin irrottamisen jopa kokonaan itse julkaisukanavasta. 
Avoimen vertaisarvioinnin määritteleminen on paitsi hankalaa ajoittain myös ristiriitaista. Siinä missä avoin vertaisarviointi merkitsee toisille sokkoarvioinnista poikkeavaa arviointia, jossa sekä tekijä että arvioitsija ovat tiedossa, toisille kyse on menettelystä, jossa arviointilausunnot julkaistaan artikkelien ohessa. Toisille avoin vertaisarviointi merkitsee näiden erilaisia yhdistelmiä ja/tai muita uusia menetelmiä, joissa arviointi esimerkiksi joukkoistetaan vertaisille tai mahdollistetaan myös muiden kuin vertaisten tekemä arviointi. Kuten avoin tiede, myös avoin vertaisarviointi on näin sateenvarjokäsite, joka sulkee sisäänsä erilaisia avoimen arvioinnin aloitteita, ominaisuuksia sekä käytännön tason kokeiluja ja menetelmiä. Avointa vertaisarviointia käsitelleet tutkimukset ovat nostaneet esiin myös monia avoimeen arviointiin liittyviä hankalasti vastattavia kysymyksiä ja kipukohtia. Arvioitsijan identiteetin kertominen saattaa tehdä arviointiprosessista tekijän näkökulmasta reilumman mutta samalla arvioitsijan saattaa olla vaikea toteuttaa arviointi täysin vilpittömästi. Aikaisen uravaiheen tutkijan saattaa olla hankala kritisoida rehellisesti edistynyttä alansa tutkijaa oman tutkijanuransa edistämisen näkökulmasta. Arvioinnin laatuun saattaa myös vaikuttaa pyrkimys olla loukkaamatta ketään. Vastavuoroisuus on yksi vahvimmista ihmisen käyttäytymiseen vaikuttavista tekijöistä ja myös tutkijoilla ihmisinä on taipumus kohdella muita kuten heitä itseään kohdellaan ${ }^{2}$. Perinteisen vertaisarvioinnin anonymiteetti voi joissakin tilanteissa tarjota välttämättömän turvapaikan arvioinnin älylliselle rehellisyydelle, vaikka sen voidaan samalla katsoa mahdollistavan myös epätoivottua ja epäreilua käyttäytymistä. Joissakin avoimen vertaisarvioinnin kokeiluissa onkin todettu, että avoimuus on lisännyt arvioitsijoiden kieltäytymistä arvioinnin tekemisestä. Kieltäytymisellä on suora vaikutus myös toimittajan tehtävien lisääntymiseen.

Tieteellisellä vertaisarvioinnilla on kaksi tehtävää: 1) arvioida tutkimusta teknisesti käytetyn metodologian pätevyyden ja oikeellisuuden, analyysin ja argumentaation suhteen, ja 2) avustaa toimituksellista valikointia arvioimalla myös tutkimuksen uutuutta ja vaikuttavuutta. Tutkimustulosten nopeampaan julkaisemiseen tähtäävissä tieteellisissä aikakauslehdissä, kuten PLOS ONE ja PeerJ, on omaksuttu arviointitapa, jossa arviointi keskittyy ainoastaan ensimmäiseen edellä mainituista tehtävistä eikä artikkelin julkaisemiseen näin vaikuta toimituksellinen näkemys aiheen ajankohtaisuudesta, trendikkyydestä tai hyvin vaikeasti arvioitavasta uutuusarvosta. Ennen ja nyt -lehden avoimen ja joukkoistetun vertaisarvioinnin kokeilussa on puolestaan otettu huomioon nämä molemmat tehtävät. Vastaavanlaisia avoimuutta hyvin laajasti vertaisarvioinnissa menestyksekkäästi soveltaneita avoimia tieteellisiä aikakauslehtiä ovat muun muassa Atmospheric Chemistry and Physics (ACP) ja sen useat European Geosciences Unionin alla toimivat sisarjournaalit sekä tieteellinen kustantaja Copernicus. ACP:n monivaiheinen arviointikonsepti perustuu kaksivaiheiseen avoimen julkaisemisen prosessiin, johon sisältyy useita vertaisarvioinnin ja vuorovaikutteisen keskustelun vaiheita ${ }^{3}$. Eri tutkimusyhteisöjen tarpeiden mukaan räätälöitävissä oleva konsepti on kokemusten perusteella kyennyt vastaamaan nopeasti kehittyvän tieteellisen vaihdon ja laadunvarmistuksen haasteisiin alhaisin kustannuksin ja taloudellisesti kestävällä tavalla. ${ }^{4}$ 


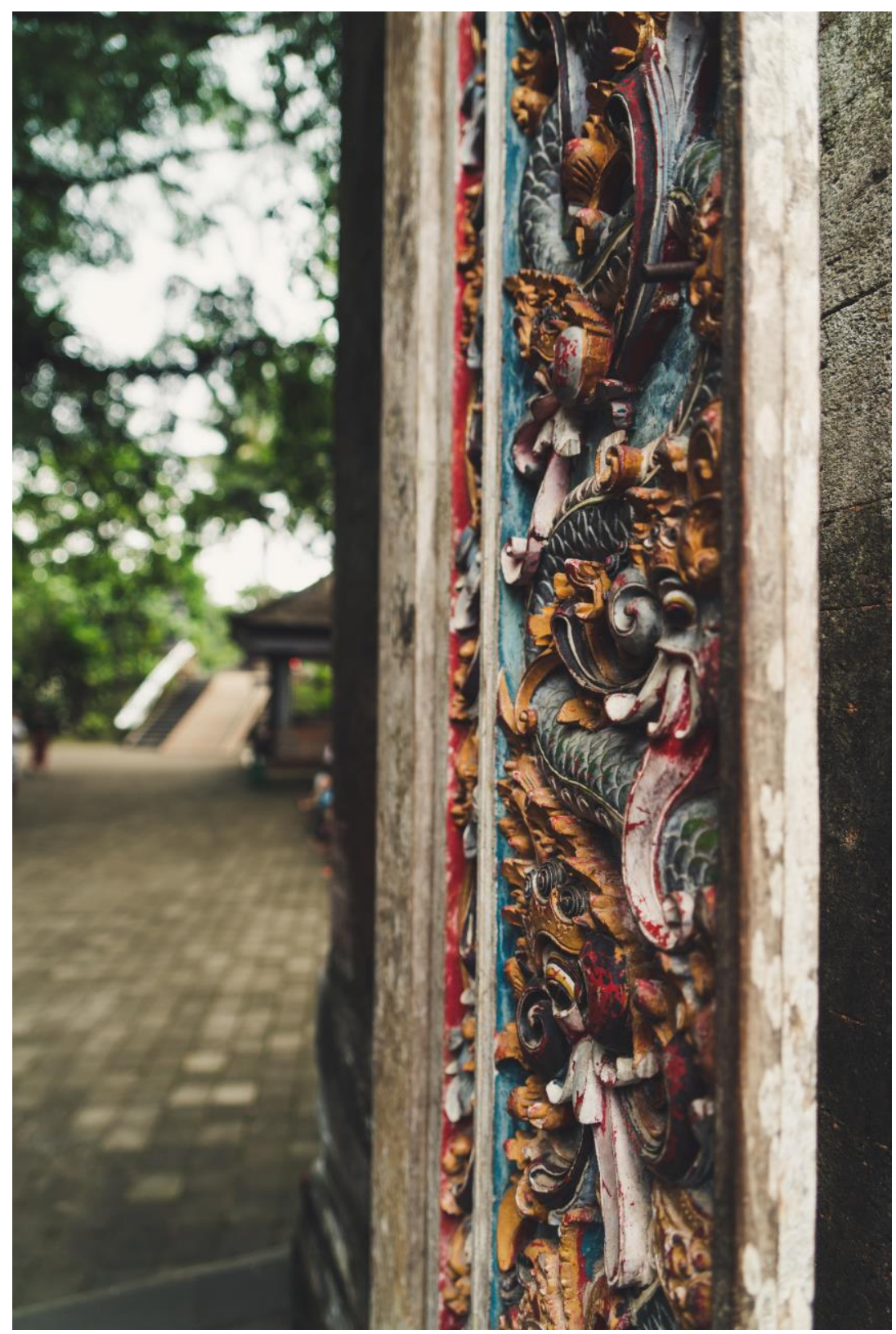

Balilaisen temppelin ovi. Kuva: Paolo Nicolello, Unsplash

Kuten vierailevan päätoimittajan Olli Kleemolan kirjoittamassa johdannossa todetaan, joukkoistetulla vertaisarvioinnilla voidaan tavoitella arviointivastuun jakamista, arvioinnin laadun parantamista ja tutkijoiden työtaakan vähentämistä. Positiivinen palaute Ennen ja nyt -lehden kokeilusta kertoo, että vastaavanlaisille kokeiluille on monessakin mielessä paikkansa. Toisaalta on totta, että avoin vertaisarviointimalli saattaa myös lisätä tutkijalta vaadittavia ponnisteluja prosessiin sisältyvän vuorovaikutteisuuden eri muodoissa. Johdannossa esitettyyn kysymykseen, kasvattaako avoin toimintamalli ideavarkauden riskiä, toteaisin, että ideoiden julkaiseminen mahdollisimman varhaisessa vaiheessa saattaa jopa vähentää sitä ja 
lisätä samalla yhteistyötä, mikäli idean julkaiseminen tehdään jo tässä kohtaa tekijänsä/tekijöidensä nimiin. Tilanne on vastaavanlainen kuin tutkimustulosten kohdalla. Ennen vertaisarviointia tapahtuva avoin käsikirjoituksen julkaiseminen esimerkiksi ArXiv-palvelimella poistaa muilta mahdollisuuden lukea alustavat tulokset omiin nimiinsä, koska ne on todistettavasti ja viitattavasti julkaistu tekijänsä nimiin jo tässä vaiheessa tutkimusprosessia. Pitkäkestoisessa ja täysin suljetussa vertaisarviointiprosessissa riski saattaa olla jopa suurempi. Avoimen vertaisarvioinnin prosessissa on täten monien muiden avointen toimintamallien tavoin muistettava huolehtia viitattavuudesta, saavutettavuudesta ja löydettävyydestä.

Avoimen vertaisarvioinnin puolestapuhujat vetoavat usein siihen, että arvioitsija saa työstään tunnustusta akateemisten ansioiden muodossa. Jotta vertaisarviointi kerryttäisi tutkijan ansioita, on tutkimuksen ja tutkijan arvioinnin järjestelmää ensin muutettava kansainvälisessä tiedeyhteisössä. Suomessa hiljattain julkaistu kansallinen suositus vastuullisesta tutkijanarvioinnista ${ }^{5}$ ja Tutkimuseettisen neuvottelukunnan (TENK) uusi ansioluettelomalli ${ }^{6}$ ovat askelia eteenpäin. Matka yksittäisen arvioitsijan tai arviointiryhmän käytännön työhön sekä tutkimusorganisaatioiden ja tutkimusrahoittajien linjauksiin ja ohjeistuksiin on kuitenkin pitkä, mutta ei mahdoton. Vuorovaikutteisuus arviointiprosessissa on samalla eräänlainen vaikuttavuuden ilmentymä, joka linkittyy avoimuuden näkökulmasta välttämättömään arviointikulttuurin muutokseen laajemminkin. Avoimen vertaisarvioinnin yleistyminen mutta myös parempi tutkimuksen laadunvarmistus, joka ottaa aiempaa tarkemmin huomioon paitsi julkaisemisen myös esimerkiksi tutkimusaineiston tai koodin ja algoritmin laadun, edellyttää muutoksia nykyisessä tutkimuksen arviointikulttuurissa. Yhteistyötä ja avointa tiedon ja tuotosten jakamista korostavassa tiedepoliittisessa ilmapiirissä ei yksin riitä, että arvioinnissa huomioidaan tieteellinen ja koulutukseen liittyvä toiminta monipuolisesti. On pystyttävä ottamaan huomioon myös tieteeseen olennaisesti kuuluva yhteisöllisyys. Mertonin tieteen ideaaleista kommunalismi kuvaa hyvin sitä, miten tutkimus rakentuu aina tutkijoiden yhteistyössä, nojaa ja tulee mahdolliseksi sekä legitiimiksi toisten tutkijoiden työn kautta. Nykyinen tutkimuksen arviointi perustuu kuitenkin korostuneesti yksilön arviointiin ja tutkijoiden väliseen kilpailuun niin tutkimusrahoituksessa, rekrytoinneissa kuin uralla etenemisessäkin. Arviointi- ja kannustinjärjestelmä, joka arvostaa yksilön saavutusten ja prestiisin rinnalla tai sijaan vahvasti myös yhteisöllisyyttä, kykenisi paremmin tunnistamaan tieteen ja yhteiskunnan edistämiseen liittyvän toiminnan.

Mikä siis estäisi meitä muuttamasta esimerkiksi kansallisesti julkaisun tekijyyden käsitystä suuntaan, jossa myös vertaisarvioitsijat luetaan tekijöiksi? Jo nyt avoimen vertaisarvioinnin menetelmin arvioiduissa julkaisuissa mainitaan usein vertaisarvioitsijat nimeltä. Täten esimerkiksi opetus-ja kulttuuriministeriön (OKM) kansallinen julkaisutiedonkeruu voitaisiin toteuttaa siten, että myös vertaisarvioitsijat kirjataan tilastoinnissa. Näin tutkijoiden tekemä työ voidaan tehdä paitsi näkyväksi myös mitattavaksi. Samalla luodaan kannustin avoimeen vertaisarviointiin. Yhtä lailla olisi kuitenkin pystyttävä tunnistamaan 
myös perinteisen vertaisarvioinnin menetelmin tehty tutkijan työ kirjaamalla tieto vertaisarvioinneista julkaisukanavan tarkkuudella tutkimustietojärjestelmään. Todennäköisintä nimittäin on, että käytännön tasolla toimivimmat uudenlaiset tieteellisen vertaisarvioinnin käytännöt syntyvät uusia läpinäkyviä ja avoimia menetelmiä, digitaalista teknologiaa ja perinteisen vertaisarvioinnin vahvuuksia joustavasti yhdistellen.

Nähtäväksi jää, miten uudenlaisen avoimuuden, vastuullisuuden ja vaikuttavuuden vallankumous toteutuu tieteen ja tutkimuksen käytännön tasolla. Olemme nyt vasta vaiheessa, jossa luodaan uusia periaatteita, kannustimia ja rakenteita tieteen edistymiselle. Ennen ja nyt -lehden kokeilu on hyvä esimerkki siitä, miten tiedeyhteisö osallistuu itse omista lähtökohdistaan käsin näiden luomiseen. Tieteen edistyminen tarvitsee vastaavanlaisia alhaalta ylös -kontribuutioita ja kokeilujen rajattomuutta tieteellisten lehtien toimittajilta ja toimituskunnilta. Samalla on muistettava, että avoin vertaisarviointi on aina osa epätäydellistä ja inhimillistä, monenlaisten valtasuhteiden värittämää tiedemaailmaa ja laajempaa tiedejärjestelmää, jossa vaikuttavat myös esimerkiksi tutkimuksen rahoituksen rakenteet. Erilaiset yhdistelmät perinteisen vertaisarvioinnin vahvuuksia ja läpinäkyvän arvioinnin hyveitä ovat tästä huolimatta jo nyt valjastettavissa vertaisarvioinnin vastuullisuuden ja tieteen laadun edistämiseen. 


\section{Lähteet}

David, P. A. (2013). 'The Historical Origins of 'Open Science': An Essay on Patronage, Reputation and Common Agency Contracting in the Scientific Revolution. Capitalism and Society." Vol. 3, Issue 2, Article 5, 2008. (https://ssrn.com/abstract=2209188) https://doi.org/10.2202/1932-0213.1040

Cialdini, R. (2001). "Harness the science of persuasion." Harvard Business Review, 72, 9. (http://www.vidartop.no/uploads/9/4/6/7/9467257/harnessing_the_science_of_persuasion.pdf)

Pöschl, U. (2012). "Multi-stage open peer review: scientific evaluation integrating the strengths of traditional peer review with the virtues of transparency and self-regulation." Frontiers in Computational Neurosciences, Vol 6, Article 33. (https://doi.org/10.3389/fncom.2012.00033) https://www.frontiersin.org/files/Articles/12032/fncom-06-00033-r2/image_m/fncom-06-00033-g001.jpg https://doi.org/10.3389/fncom.2012.00033

Vastuullisen tutkijanarvioinnin työryhmä (2020). Tutkijanarvioinnin hyvät käytännöt. Vastuullisen tutkijanarvioinnin kansallinen suositus. Vastuullisen tieteen julkaisusarja 5:2020.

https://doi.org/10.23847/isbn. 9789525995275

TENK (2020). Tutkijan ansioluettelomalli. Tutkimuseettisen neuvottelukunnan suositus 2020. (http://www.tenk.fi/sites/tenk.fi/files/TENKin ansioluettelomalli 2020.pdf) 
${ }^{1}$ P. A. David, (2013), "The Historical Origins of 'Open Science': An Essay on Patronage, Reputation and Common Agency Contracting in the Scientific Revolution," Capitalism and Society, Vol. 3, Issue 2, Article 5, 2008. (https://ssrn.com/ab$\underline{\text { stract }=2209188 \text { ) }}$

${ }^{2}$ R. Cialdini (2001), "Harness the science of persuasion. Harvard Business Review, 72, 9. (http://www.vidartop.no/uploads/9/4/6/7/9467257/harnessing the science of persuasion.pdf)

${ }^{3}$ U. Pöschl (2012), "Multi-stage open peer review: scientific evaluation integrating the strengths of traditional peer review with the virtues of transparency and self-regulation," Frontiers in Computational Neurosciences, Vol 6, Article 33. https://www.frontiersin.org/files/Articles/12032/fncom-06-00033-r2/image m/fncom-06-00033-g001.jpg

${ }^{4}$ U. Pöschl (2012), "Multi-stage open peer review: scientific evaluation integrating the strengths of traditional peer review with the virtues of transparency and self-regulation," Frontiers in Computational Neurosciences, Vol 6, Article 33. (https://doi.org/10.3389/fncom.2012.00033)

${ }^{5}$ Vastuullisen tutkijanarvioinnin työryhmä (2020). Tutkijanarvioinnin hyvät käytännöt. Vastuullisen tutkijanarvioinnin kansallinen suositus. Vastuullisen tieteen julkaisusarja 5:2020. (https://doi.org/10.23847/isbn.9789525995275)

${ }^{6}$ TENK (2020). Tutkijan ansioluettelomalli. Tutkimuseettisen neuvottelukunnan suositus 2020. (http://www.tenk.fi/sites/tenk.fi/files/TENKin ansioluettelomalli 2020.pdf) 